\title{
ASSESSING STUDENT PERFORMANCE
}

\author{
by LaVerd John, Ed.D. \\ Adjunct Assistant Professor \\ Embry-Riddle Aeronautical University \\ College of Continuing Education, Hill Center
}




\title{
ASSESSING STUDENT PERFORMANCE
}

\author{
by LaVerd John, Ed.D
}

One of the essential conditions for effective learning is provision for transfer. Effective teachers provide for application of learned principles in real life situations. The only evidence that a student has learned is demonstrated in his/her behavior change. Therefore, student performance is the criterion upon which effective learning and teaching may be measured.

Understanding the sequential phases of learning and carefully planning lesson presentations to move the student through each phase are skills a teacher must acquire and use. The first phase of learning is perception. The student is stimulated by hearing, seeing, smelling, tasting or touching. Teachers usually plan and prepare a wide variety of experiences which will help the student perceive what is to be learned. Methods and techniques of lesson presentation along with effective audio/visual aids are used to enhance the student's chances of receiving the appropriate perceptions.

Perception is an essential phase of learning, but it is only the first phase. That which a student perceives passes with the second. A spoken word, a viewed picture, a body gesture, a projected feeling or any other form of communication is perceived only as long as the stimulus is present. As soon as the stimulus is removed, the perception ends. Very few of the words that are spoken are retained more than a few seconds.
This makes the second phase of learning, which is conceiving that which has been perceived, more important than the first phase. It is the concept formed in the mind of the student that will remain and will to some degree change the lens through which the student will view the world. Concepts program us to see what we believe rather than the usually accepted theory that we believe what we see.

Teachers should be as concerned about that which has been conceived as they are about that which has been presented for the student to perceive. Some students were asked to form in their minds the image of a cat. The word cat was perceived by each student, but the concept formed by each was different. One conceived a black cat, another a white cat, another a yellow cat. No two students conceived the same cat. The teacher had in mind a Caterpillar Tractor. From the same perception developed a wide variety of conceptions and none was the same as the teacher's.

When the students form a wide diversity of concepts related to the word cat which is a very concrete word, it is obvious that a wider diversity of concepts would be formed from a more abstract word; therefore, teachers must assess the appropriateness of the concepts formed by the students from that which has been perceived.

At this point, we see the importance of presenting appropriate information in a 
manner that may be perceived correctly by the student so that appropriate concepts may be formed. However, that which is perceived and that which is conceived may lie dormant and be of little value to the student even though he/she has scored high on the examinations given by the teacher. It is not until the perceptions and conceptions are transformed into action that there is evidence that learning has taken place. Behavior change is the objective of the learning process and should receive the greatest emphasis.

The task of assessing student performance requires the teacher to focus the lesson presentation upon the behavior change which is expected as perceptions are received and concepts are formed in the minds of the students. An excellent example of focusing upon the application of learning may be seen in the MAS 605, Research Methods and Statistics Class. The students in this class are required to call upon all of the perceptions and conceptions they have acquired during their entire public and college experiences and focus them upon selecting a problem, stating a hypothesis, collecting data, presenting data, evaluating data, drawing conclusions and making recommendations. All the students have perceived and conceived over the years is brought into focus to successfully complete the research study.

Examples where the teacher has not provided the opportunity for application or has not made the connection between perceiving, conceiving and applying may be seen in the following cases: A student was failing in his math. To check the problem, the student was asked to multiply 305 by 217. The student had no mode of attack he could use to solve this problem. As he sat looking at the math problem he said, "It is going to freeze tonight and my dad is working like crazy trying to get all of the apples picked before they are frozen."

When asked, "Do you have apples for sale?"

He replied, "Yes, we do."

"How much do you charge for a bushel?"

"Two and a half."

"How many bushels could I buy with ten dollars?"

"Four," he replied without hesitation.

It is obvious that the student had not made the connection between working math problems in a math class and the real life use of math at the orchard.

Another student was unable to read. He had no word attack skills. However, when asked to read along with the writer, it was discovered that the student could read when he became interested in the content of the printed material, but he could not read when he was just trying to recognize words. No doubt the teachers who had tried to teach him to read would say, "Get your reading books out. We are going to have reading." This student perceived these words to mean that reading has content of its own and that reading is an end rather than a means to an end; therefore, he had not seen the connection between reading skills and seeking information. Acquiring reading skills quickly becomes boring unless the 
application of these skills are understood. Boredom and failure are closely connected.

A simple, easy way for a teacher to check the concepts which have been formed and the applications which have been made may be accomplished without undue hardship on the student or the teacher. The teacher may ask the students to write two concepts which have been acquired during the class period. These concepts provide an excellent opportunity for the teacher to check the appropriateness of his lesson presentation and/or the class discussion.

At the beginning of the next class period, the teacher may ask each student to write a brief statement related to the application of the concepts acquired in the previous class. This provides the teacher with an excellent opportunity to evaluate the student's performance in real life.

"You can't guide anything that is stopped", was a concept one student submitted. At the beginning of the next class, he stated, "I tried to guide my car before I started it and discovered that it was impossible to guide it while it was stopped. Even though it was moving in the wrong direction when I backed away from the curb, I could guide it into the right direction as long as I kept it in motion.

I made use of this same basic principle when I guided my son into his home work. I called him to me without telling him what I wanted him to do. This got him in motion. Then I led him into the den where he would have a quiet place to study. Our walk together gave me the opportunity to lead him into the appropriate place for effective study and guide him into the step by step approach to problem solving. I discovered that motion was essential before guiding can take place."

Understanding the sequential phases of learning and carefully leading students from perception to conception to real life application is essential if learning is to take place effectively.

Student evaluation may be appropriately made based upon student performance if the teacher has created a learning environment which required the student to apply, in real life situations, that which has been perceived and conceived during the course of study. 